\title{
AGE AND SEX-RELATED STRUCTURAL AND FUNCTIONAL CHANGES OF BONE REMODELING DURING SIMULTATE ABDOMEN CT-SCANNING
}

DOI: 10.36740/WLek202001117

\author{
Nazar M. Kostyshyn, Liubov P. Kostyshyn, Mechyslav R. Gzhegotskyi \\ DANYLO HALYTSKY LVIV NATIONAL MEDICAL UNIVERSITY, LVIV, UKRAINE
}

\begin{abstract}
The aim of investigation was to study the structural and functional conditions of cortical and trabecular layers of lumbar vertebrae $\mathrm{L}_{1}-\mathrm{L}_{5}$ in different age groups.

Materials and methods: In order to assess BMD of the lumbar vertebrae 102 people18 to 75 years old was examined. Study of bone mineral density cortical and trabecular layer of lumbar vertebrae $\left(\mathrm{L}_{1}-\mathrm{L}_{5}\right)$ performed by computed tomography in Hounsfield Units (HU) in terms of standard deviation (SD).

Results: The results of computed tomography showed a direct relationship of bone mineral density of lumbar vertebrae with age of examined persons. Osteoporosis and osteopenia was registered in $15 \%$ of men and $30 \%$ women in middle adulthood, in late adulthood - $35 \%$ and $50 \%$ respectively. During early old age osteopenia and osteoporosis are observed in $37,5 \%$ and $25 \%$ of men and $26 \%$ and $64 \%$ women. 0steoporosis in the middle old age has been reported in $50 \%$ of men and $75 \%$ of women

Conclusions: Results of the study showed a direct link between mineral density, age and gender. The middle adulthood age period was characterized by the highest mineral mass compared with the other age periods. Then there is a loss of bone mass throughout life, and with the onset of aging osteopenia and osteoporosis are recorded. It was investigated that in the early old age, loss of bone mass is mainly observed in female.
\end{abstract}

KEY WORDS: bone, bone mineral density, remodeling

Wiad Lek. 2020;73(1):91-94

\section{INTRODUCTION}

Bone tissue is a metabolic active system and its functioning ensured by the process of remodeling, which consists in the continuous replacement of bone plates, the formation of new osteons and trabeculae on the site of the resorbed ones. This process maintains a constant mineral bone mass throughout the entire life $[1,2,3]$. The structural and functional conditions of bone tissue depends on many factors, epidemiological studies indicate the dependence of the formation of bone tissue on age, sexual, ethnic characteristics, etc. $[4,5]$. Randomized, multicentre studies in Europe and the United States have demonstrated that in the puberty and post-puberty period, bone mass is actively increasing, reaching its maximum by an average of 25-30 years. Then comes the period of equilibrium. The physiological decline in bone mass begins at approximately 35 years of age and increases in the first 5-10 years after menopause in women, $2-3 \%$ per year. In men loss of bone tissue is $0,3-0,4 \%$ per year. From 65-70 years, the rate of loss of bone tissue is reduced and make $0,2-0,3 \%$ per year for both sexes $[6,7,8]$.

The imbalance of bone remodeling leads to the formation of osteopenia and osteoporosis - systemic or local disease of the skeleton with decreasing of bone mineral mass. This leads to increasing of bone fragility with subsequent risk of fractures. Particularly in women, the development of osteoporosis is associated with loss of bone mineral density (BMD), which occurs most often during menopause. At the same time, the deficiency of estrogen leads to a slower inhibition of osteoclasts, a decrease in the activity of osteoblasts, increases the sensitivity of cells to parathyroid hormone, enhances the synthesis of pro-reactive cytokines (IL-1, IL-6, IL-11, TNF) $[9,10]$.

Recent research shows that calcium, iodine, zinc and fluoride deficiencies, as well as sedentary lifestyle and bad habits can also affect the bone mineralization even in childhood and adolescence. In particular, the effect of iodine deficiency on bone tissue is indirect, but it plays a key role in the functioning of the thyroid gland hormones that are necessary in the regulation of normal growth for the development of the skeleton [11]. The problem of hypothyroidism is relevant for the endemic regions of Ukraine, which includes the Lviv region, where iodine deficiency tends to increase. Therefore, this problem is relevant for further our scientific work.

\section{THE AIM}

Investigate the structural and functional conditions of the cortical and trabecular layers of the lumbar vertebrae $\left(\mathrm{L}_{1}-\mathrm{L}_{5}\right)$ in persons of different age groups living in the Lviv region.

\section{MATERIALS AND METHODS}

In order to assess the BMD of the lumbar vertebra, 102 patients aged 18 to 75 years were examined. The patients 


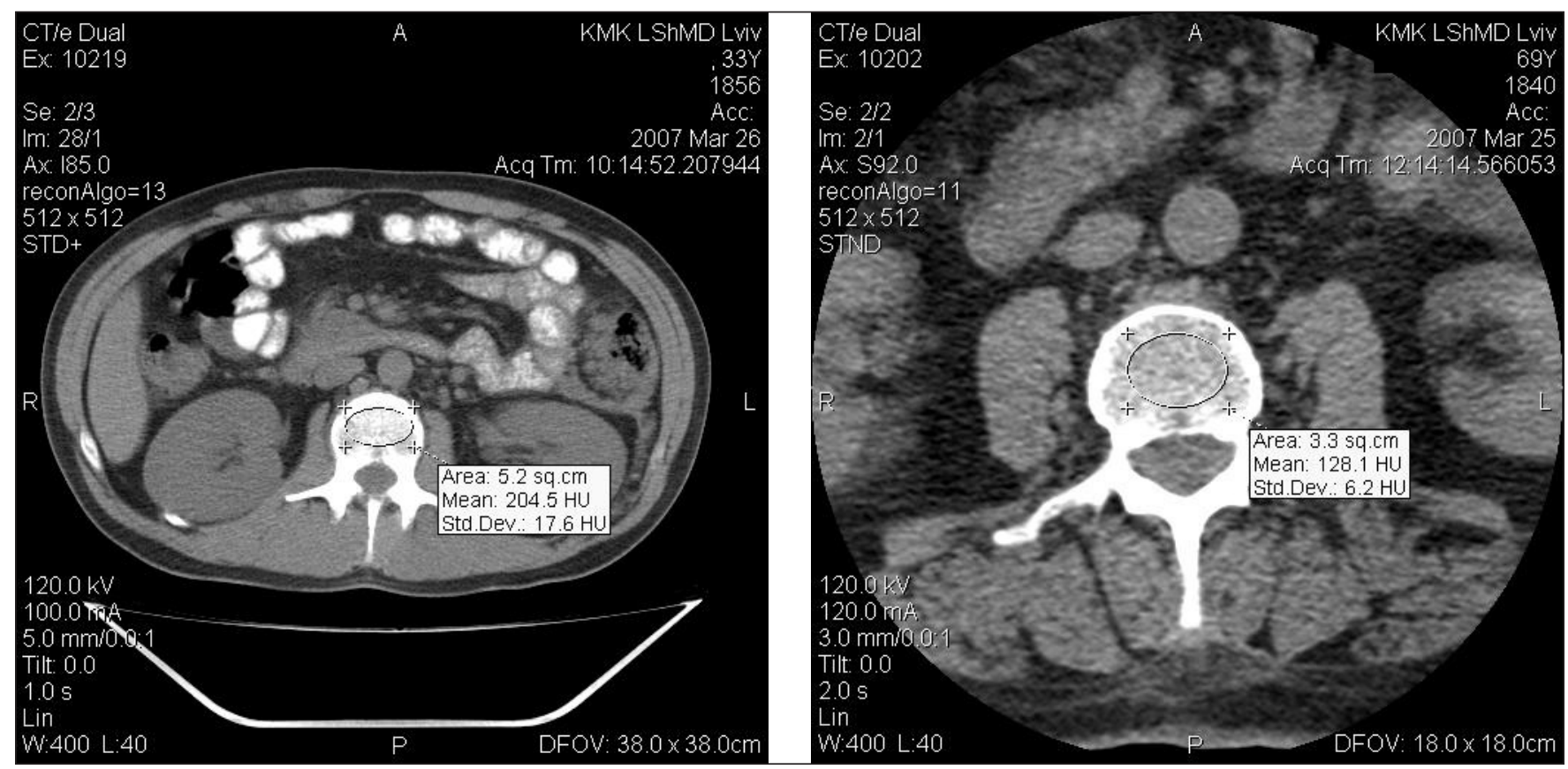

Fig. 1. Vertebral attenuation measurement of BMD (HU) using the ROI method

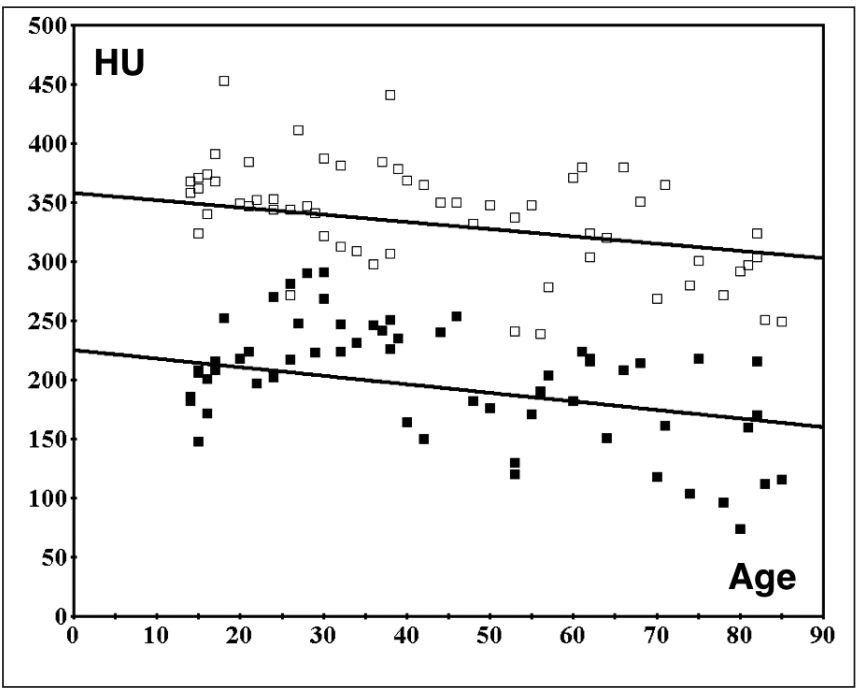

Fig. 2. BMD (HU) of trabecular ( $\square$ ) and cortical ( $\square$ ) layers L1-L5 in men

were divided into 10 groups that consisted of 5 age periods: early adulthood (18-30 years), middle adulthood (30-45 years), late adulthood (45-60 years), early old age (60-75 years) middle old age (75-90 years). Investigation of mineral density of lumbar vertebrae bone tissue $\left(\mathrm{L}_{1}-\mathrm{L}_{5}\right)$ was performed by computer tomography (CT) GE / e Dual CT scanner using a standard gauge with a thickness of $3 \mathrm{~mm}$, a peak voltage of $120.0 \mathrm{kV}$ and a current of $496 \mathrm{~mA}$. Data was processed using the eFilm Workstation 3.4.0, 34 bit (Merge Healthcare, USA, 2013) program on the Windows 7 Professional SP 1, 32 bit (Microsoft, USA, 2009) system.

The instrument was calibrated using phantoms of water, air, ethanol and potassium phosphate, which were scanned together with the subject. The values of the sections were corrected by the formula:

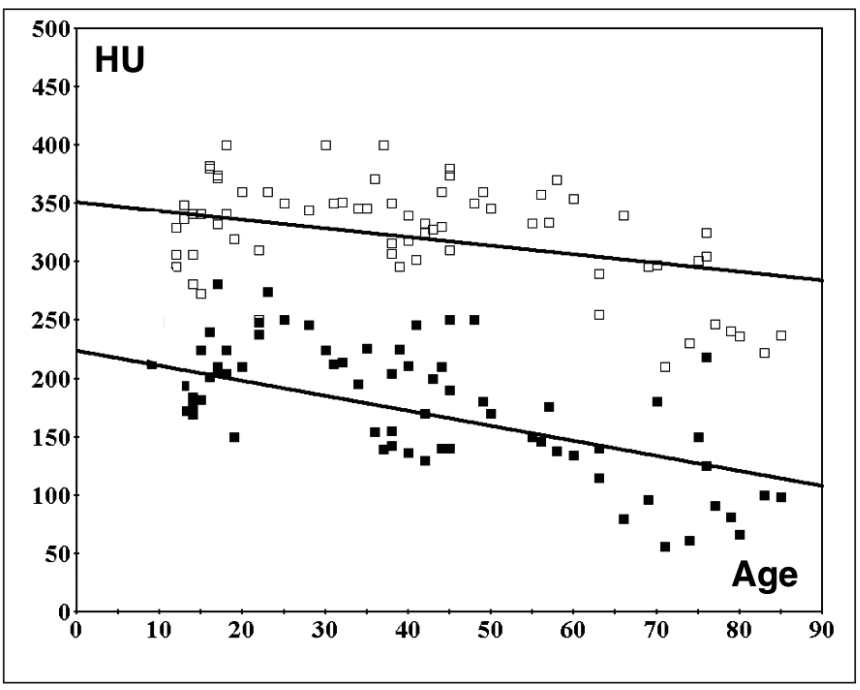

Fig. 3. BMD (HU) of trabecular ( $\square$ ) and cortical ( $\square$ ) layers L1-L5 in women

$\mathrm{HU}=\mathbf{1 0 0 0}\left(\mathrm{HU}_{\mathrm{b}}-\mathrm{Hu}_{\mathrm{w}}\right) / \mathrm{HU}_{\mathrm{w}}-\mathrm{HU}_{\mathrm{a}}$ where:

$\mathrm{HU}_{\mathrm{b}}$ - the average density of the scanning area of the spongy bone,

$\mathrm{HU}_{\mathrm{w}}$ - the average density of the standard water in the phantom,

$\mathrm{HU}_{\mathrm{a}}$ - the average density of the standard air in the phantom. The result of each subject was calculated by the formula: $\mathrm{HU}=\mathbf{P}_{1} \mathrm{HU}_{1}+\mathbf{P}_{2} \mathrm{HU}_{2}+\ldots+\mathbf{P}_{\mathbf{n}} \mathrm{HU}_{\mathrm{n}} / \mathrm{P}_{1}+\mathrm{P}_{2}+\ldots+\mathbf{P}_{\mathrm{n}}$ where:

$\mathrm{P}$ - the number of pixels in the area of the standard scan.

Density indices of the bone tissue of the trabecular layer of the lumbar vertebrae were determined according to CT criteria in the units of Hounsfield (HU) - ROI method, with standard deviation (SD), fig 1. 
Table 1. Bone mineral density of the lumbar vertebra, HU

\begin{tabular}{|c|c|c|c|c|c|}
\hline \multirow{3}{*}{ № } & \multirow{3}{*}{$\begin{array}{c}\text { Age } \\
\text { periods }\end{array}$} & \multicolumn{4}{|c|}{ BMD (HU) } \\
\hline & & \multicolumn{2}{|c|}{ Men } & \multicolumn{2}{|c|}{ Women } \\
\hline & & Trabecular bone & Cortical bone & Trabecular bone & Cortical bone \\
\hline 1. & Early adulthood & $223,0 \pm 8,4$ & $381,6 \pm 21,8$ & $203,9 \pm 9,6$ & $367,9 \pm 10,0$ \\
\hline 2. & Middle adulthood & $245,0 \pm 9,9$ & $367,4 \pm 13,3$ & $232,8 \pm 7,7$ & $360,1 \pm 12,8$ \\
\hline 3. & Late adulthood & $197,8 \pm 16,5$ & $331,5 \pm 13,7$ & $180,9 \pm 8,9$ & $341,2 \pm 6,2$ \\
\hline 4. & Early old age & $179,3 \pm 15,5$ & $328,1 \pm 13,7$ & $119,6 \pm 13,2$ & $303,1 \pm 17,2$ \\
\hline 5. & Middle old age & $145,3 \pm 20,5$ & $287,0 \pm 10,3$ & $116,0 \pm 18,3$ & $262,8 \pm 14,2$ \\
\hline
\end{tabular}
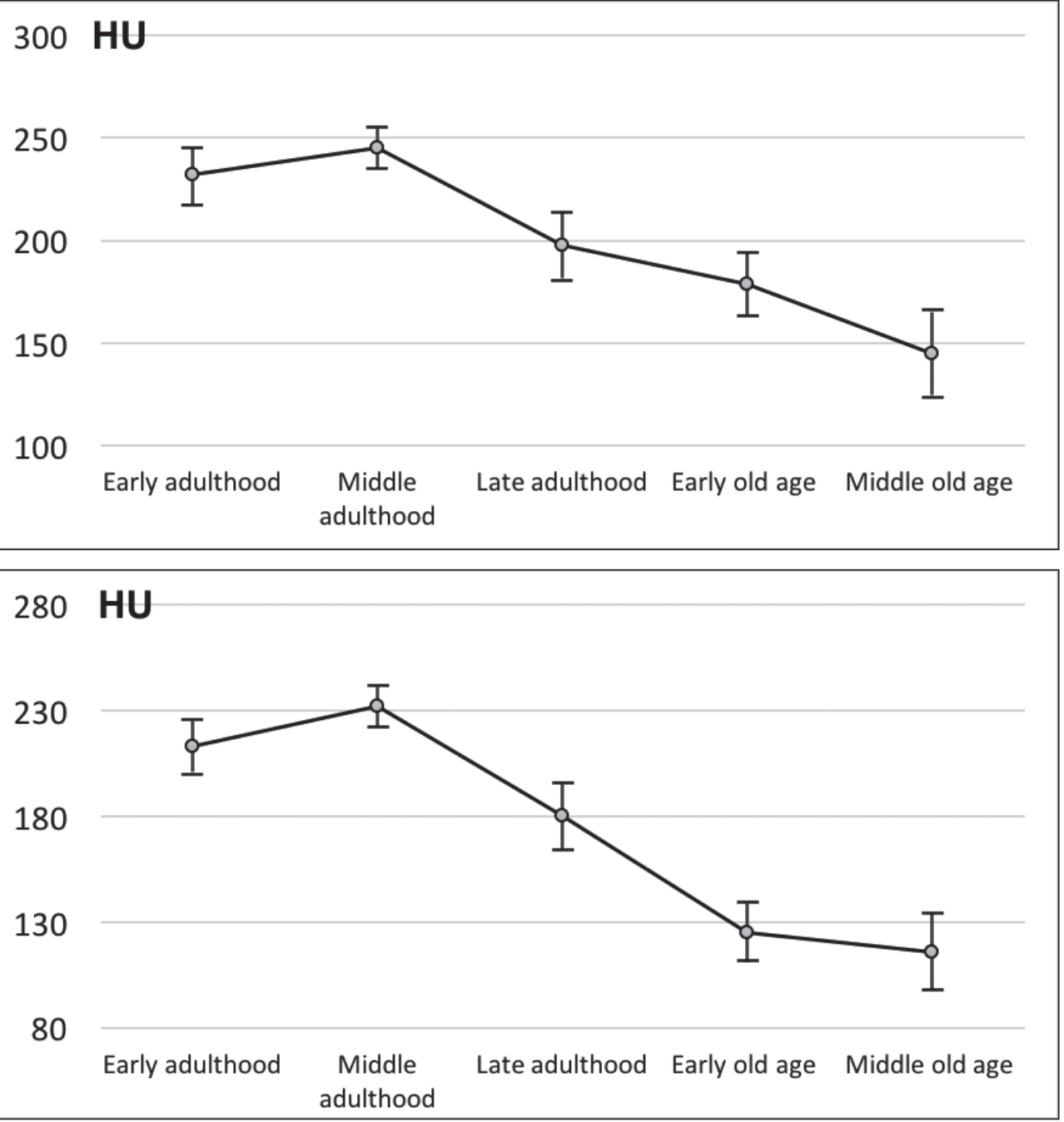

Fig. 4. Age dependence of BMD (HU) of lumbar vertebrae in men
Average values of the mineral density were more than +216.7 - considered as normal BMD (>-1 SD), the value from +216.7 to $+148.6-$ osteopenia, $(-1-(-2,5)$ SD) and were less than +148.6 - osteoporosis $(\leq 2.5 \mathrm{SD})[1,10]$.

\section{RESULTS AND DISCUSSION}

The results showed a direct dependence of BMD of the trabecular and cortical layers of the lumbar vertebrae to the age and sex. It has been established that mineral bone mass is actively increasing in early adulthood, tab. 1, fig 2, 3 .

In males of this age group, the mineral density of bone tissue was $223,0 \pm 8,4$ for the trabecular layer and 381,6 \pm
21,8 for the cortical layer, respectively. For females: for the trabecular layer - 203,9 $\pm 9,6$ and for the cortical layer 367,9 $\pm 10,0$, respectively. Middle adulthood was characterized by the highest mineral mass, compared with other age periods. Mineral density $-245,0 \pm 9,9$ and 367,4 $\pm 13,3$ for trabecular and cortical layers in males and 232,8 $\pm 7,7$ and $360,1 \pm 12,8 \mathrm{fe}-$ males, respectively. As a result, osteopenia was recorded in 15 $\%$ of the examined men and in $30 \%$ of the female population.

Late adulthood is characterized by a gradual loss of bone mass. Especially this dependence is observed in the examined subjects of the female sex. In particular, osteopenia was detected in $35 \%$ of men and $52 \%$ of women, and osteoporosis $-12 \%$ and $24 \%$ respectively. The reason 
for accelerated bone remodeling in this age is the lack of sex hormones, which is typical during menopause. The average density of bone tissue in the subjects of the late adulthood was $197,8 \pm 16,5$ and $331,5 \pm 13,7$ for men and $180,9 \pm 8,9$ and $341,2 \pm 6,2$ for women. During early old age osteopenia and osteoporosis are observed in $37,5 \%$ and $25 \%$ of men and $26 \%$ and $64 \%$ of women. Osteoporosis in the middle old age has been reported in $50 \%$ of men and $75 \%$ of women, fig 4,5 .

\section{CONCLUSIONS}

The mineral density of the trabecular and cortical vertebrate layers in male and female was estimated using CT. It has been established that mineral bone mass is actively increasing in early adulthood. The middle adulthood age period was characterized by the highest mineral mass compared with the other age periods. Then there is a loss of bone mass throughout life, and with the onset of aging osteopenia and osteoporosis are recorded. It was investigated that in the early old age, loss of bone mass is mainly observed in female subjects. The reason for accelerated bone remodeling in this age is the lack of sex hormones that occurs during the menopause.

\section{REFERENCES}

1. Lacedra SA, Matuoka RI, Macedo RM et al. Bone quality associated with daily intake of coffee: a biochemical, radiographic and histometric study. Brazilian Dental Journal. 2010; 21(3): 199-204.

2. Zemel BS, Leonard MB, Kelly A et al. Height adjustment in assessing dual energy $\mathrm{X}$-ray absorptiometry measurements of bone mass and density in children. The Journal of Clinical Endocrinology and Metabolism. 2010; № 95(3): 1265-1273.

3. Budoff MJ, Hamirani YS, Gao YL et al. Measurement of thoracic bone mineral density with quantitative CT. Radiology. 2010;257(2): 434-440.

4. Abdrakhmanova ZS. Bone densitometry and computed tomography in the evaluation thresholds of mineral density of the vertebral bodies as a risk factor of fractures. Abstract of the PhD dissertation. Tomsk; 2006, p. 1-19.

5. Povoroznyuk VV, Dzerovich NI. The quality of the trabecular bone in women of different age. Pain. Joints. Spine. 2011; 4: 29-31.

6. Baum T, Carballido-Gamio J, Huber MB et al. Automated 3D trabecular bone structure analysis of the proximal femur-prediction of biomechanical strength by CT and DXA. Osteoporos Int. 2010; 21: 1553-1564.

7. Bachrach LK, Sills IN. Clinical report - Bone densitometry in children and adolescents. Pediatrics. 2011; 127: 189-194.

8. PovoroznyukVV, Musienko AS, Dzerovich NI. Trabecular bone score, bone mineral density and 10-year fracture probability in Ukrainian men of different ages. Pain. Joints. Spine. 2013; 3(11): 52-55.
9. Schutska GV, Hudyma AA, Boris RM. Features remodeling of bone tissue in osteoporosis and conditions hypokinetic trauma experiment. Current problems of transport medicine. 2013; 1: 112-117.

10. Waung JA, Bassett JH, Williams GR. Thyroid hormone metabolism in skeletal development and adult bone maintenance. Trends in Endocrinology and Metabolism. 2012; 23(4): 155-162.

11. Pickhardt PJ, Lee LJ, Munoz del Rio A, at al. Simultaneous screening for osteoporosis at CT colonography: bone mineral density assessment using MDCT attenuation techniques compared with the DXA reference standard. Journal of Bone and Mineral Research. 2011; 26(9): 2194-2203.

The article is a fragment of the complex research work of the Department of Normal Physiology, Danylo Halytsky National Medical University (Lviv, Ukraine) "Investigation of the role of systemic and paracrine regulatory mechanisms in providing homeostasis of functional and metabolic parameters of the organism under conditions of adaptation to the action of natural agents (State registration number 0116U004510).

\section{ORCID and contributionship:}

Nazar M. Kostyshyn - 0000-0003-0341-5853 A,B,D,F

Luibov P. Kostyshyn - 0000-0002-9223-3543 ${ }^{\mathrm{C}}$

Mechyslav R. Gzhegotskyi-0000-0003-0561-205X ${ }^{E}$

\section{Conflict of interest:}

The Authors declare no conflict of interest

\section{CORRESPONDING AUTHOR Nazar M. Kostyshyn \\ Department of normal physiology, Danylo Halytsky Lviv National Medical University St. Pekarskaya, 69, Lviv, Ukraine tel: +380674186220 \\ e-mail: kostyshyn.nm@gmail.com}

\section{Received: 26.04 .2019}

Accepted: 07.11 .2019

A - Work concept and design, B - Data collection and analysis, C - Responsibility for statistical analysis, D-Writing the article, $\mathbf{E}$-Critical review, $\mathbf{F}$ - Final approval of the article 